\title{
Maternal and child factors of under-five mortality in India. Findings from NFHS-4
}

\author{
Namita Patel ${ }^{\mathrm{a}}$, Jeby Jose Olickal ${ }^{\mathrm{b}, \text { * }}$ \\ ${ }^{a}$ Department of Pediatrics, All India Institute of Medical Sciences, Bhopal, India \\ ${ }^{\mathrm{b}}$ Department of Public Health, KS Hegde Medical Academy, Mangalore, India
}

\section{A R T I C L E I N F O}

\section{Keywords:}

Under-five mortality

NFHS-4

India

\begin{abstract}
A B S T R A C T
Background: Although under-five mortality has declined in India, the target is yet to be achieved. The objective of this secondary analysis was to find out the influence of maternal and child factors on the likelihood of mortality among under-five children.

Methods: The study is based on Indian National Family Health Survey-4, 2015-16 data. A stratified multistage clustering sampling technique was used. The primary outcome variable of our analysis was under-five deaths that occurred in five years preceding the data collection.

Results: Higher under-five deaths (11.7\%) were significantly observed in older maternal age, 45-49 years. For maternal education and place of residence, mothers with no education and rural residence had higher under-five mortality (5.99\% and 4.93\%, respectively). Mothers who read newspaper/magazines almost every day had lowest under-five deaths (1.99\%). Birth order $>6$ was significantly associated with high under-five mortality (11.0\%).

Conclusion: The study shows maternal, and child factors are important determinants in under-five mortality in India.
\end{abstract}

\section{Introduction}

Under-five mortality is defined as the probability of dying after birth till the age of five per 1000 live births and is used as an indicator of socioeconomic development in a developing country. It also reflects the health care status and quality of life of the population. ${ }^{1}$ Under-five mortality has declined substantially in the last three decades, dropped from 12.5 million deaths globally in 1990 to 5.9 million in 2019. India and Nigeria together contribute to one-third of these deaths. ${ }^{2}$ India has witnessed a 54\% decrease in mortality rate from 1992 to 93 to 2015-16. ${ }^{3}$ Despite of all the efforts, the proposed SDG target of under-five mortality to as low as 25 deaths per thousand live births by 2030 is yet to be achieved. ${ }^{4}$

A leading cause of under-five mortality includes poor child and maternal nutrition, pre-term birth complications, intrapartum related events and infectious diseases related causes. In addition, children's survival prospects continue to be influenced by geographic and economic inequities. There has been a decline in under-five mortality and overall improvement in children's growth, but significant geographical disparities still exist in India. ${ }^{5}$ Therefore, there is a need to explore other important causes of under-five deaths for policy formulation and guide health expenditure on child survival programmes. Ending preventable child deaths worldwide will require targeted interventions to maternal and child causes of death among under-five children. Furthermore, previous studies have reported association of child mortality with various characteristics of parents and under-five children. Hence, the objective of this secondary analysis was to find out the influence of maternal and child factors on the likelihood of mortality among under-five children.

\section{Methods}

The International Institute for Population Sciences (IIPS) and Macro International conducted the National Family Health Survey (NFHS-4) in India during 2015-16. ${ }^{6}$ NFHS-4 is a national level cross-sectional survey that provides information on population health and nutrition for India and each state/union territory. Nationally representative households' samples were selected throughout India by stratified multistage clustering sampling technique. In most of the rural areas two-stage sample design was used where villages acted as the primary sampling unit,

\footnotetext{
* Corresponding author.

E-mail address: drjebyjose@gmail.com (J.J. Olickal).
} 
while in urban areas three-stage sample design with census enumeration block as primary sampling unit was used. Primary sampling units were selected with probability proportional to population size. Data was collected in local language using computer-assisted personal interviewing (CAPI). A total of 2,59,627 maternal responses of children aged less than five years were assessed and analysed. The primary outcome variable of our analysis was under-five deaths that occurred in five years preceding the data collection. Analysis was done using STATA Version 14. Survey set analysis of NFHS-4 data was performed and weighted proportions were calculated. Maternal and child factors were analysed separately using generalized linear regression analysis. A p-value less than 0.05 was considered as statistically significant.

\section{Results}

Out of total 2,59,627 maternal responses of children aged less than five years, under-five deaths reported were 11,884 . The prevalence of under-five mortality was $4.41 \%$. Higher under-five deaths (11.7\%) were significantly observed in older maternal age, $45-49$ years $(\mathrm{p}<0.001)$. Child mortality was more among rural (4.93\%) compared to urban (3.08, $\mathrm{p}<0.001)$. Mothers with no education had a higher under-five mortality than those educated above secondary $(5.99 \%$ vs $2.15, \mathrm{p}<$ 0.001). Maternal media use (TV, radio and newspaper/magazine) was significantly associated with low under-five deaths. Mothers belonging to the poorest wealth index had three times more under-five mortalities than those who were richest $(\mathrm{p}<0.001)$. Unmarried and employed mothers significantly reported a higher under-five mortality $(5.6 \%$ and $4.97 \%$, respectively) than their counterparts. Similarly, mothers age at birth is low ( $<22$ years) then the likelihood of child death was significantly higher as compared to mothers aged $22-28$ years $(4.68 \%$ vs $3.95 \%, \mathrm{p}<0.001$ ). [Table 1 ].

The child factors associated with under-five mortality was shown in Table 2. Higher birth order significantly influenced under-five deaths compared to low birth order ( $11.0 \%$ vs $4.04 \%, \mathrm{p}<0.001)$. A male child (mortality $=4.66 \%$ ) had poor survival compared to a female child (mortality $=4.14 \%$ ). Children born as small size reported $7.9 \%$ underfive mortality, while normal-sized babies reported significantly low $(3.56 \%)$ under five mortalities $(\mathrm{p}<0.001)$.

\section{Discussion}

The study aimed to examine the effects of maternal and child factors on under-five mortality. Several maternal factors such as very young and old maternal age, rural residence, illiteracy, poor wealth index, poor awareness, unmarried and unemployment were significantly associated with high under-five mortality. We found that under-five mortality was reported significantly less in educated mothers, which was seen in concordance with a study conducted in sub-Saharan Africa and southern Asia. ${ }^{7,8}$ Several other studies have reported an association of low maternal education with poor child health outcomes. ${ }^{9,10}$ An educated mother would ensure routine health checkups, timely vaccination, proper hygiene, and a nutritious diet for her children, resulting in low morbidity and mortality.

A similar pattern of increased risk of mortality in children of young and old mothers was also observed in a prospective cohort study conducted in Delhi, India. ${ }^{11}$ An analysis of nationally representative data from South Asian nations also depicted similar results. ${ }^{12}$ These findings highlight the importance of delayed marriage and improved use of contraceptives among young people. All the maternal factors influencing childhood mortality could be supported by the fact that mothers with higher education and awareness, residing in urban areas and belonging to richer wealth index, could have a higher likelihood of utilising health services or better access to health care facilities. ${ }^{13-15}$

We also found the employment status of mothers as one of the risk factors for under-five mortality. A mother who does not work devotes more time to domestic activities and spends more time with children,
Table 1

Maternal factors of under 5 mortalities in India ( $N=259,627)$.

\begin{tabular}{|c|c|c|c|}
\hline Variable & $\begin{array}{l}\text { Number of } \\
\text { children }\end{array}$ & $\begin{array}{l}\text { Under } 5 \text { mortality n } \\
(\%)^{\mathrm{a}}\end{array}$ & $P$ value \\
\hline \multicolumn{4}{|l|}{ Maternal age (years) } \\
\hline $15-19$ & 6699 & $444(5.82)$ & \multirow[t]{7}{*}{$<0.001$} \\
\hline $20-24$ & 78,177 & $3718(4.52)$ & \\
\hline $25-29$ & 99,396 & 4077 (3.98) & \\
\hline $30-34$ & 49,005 & 2112 (4.17) & \\
\hline $35-39$ & 19,212 & $998(5.26)$ & \\
\hline $40-44$ & 5504 & $367(7.07)$ & \\
\hline $45-49$ & 1634 & $168(11.7)$ & \\
\hline \multicolumn{4}{|l|}{ Place of residence } \\
\hline Urban & 61,379 & 2157 (3.08) & \multirow[t]{2}{*}{$<0.001$} \\
\hline Rural & 198,248 & 9727 (4.93) & \\
\hline \multicolumn{4}{|l|}{ Maternal education } \\
\hline No education & 81,087 & 4875 (5.99) & \multirow[t]{4}{*}{$<0.001$} \\
\hline Primary (Class I-VIII) & 37,938 & $2021(5.36)$ & \\
\hline Secondary (Class IX-X) & 116,646 & 4419 (3.59) & \\
\hline Higher secondary and above & 23,956 & $569(2.15)$ & \\
\hline \multicolumn{4}{|l|}{ Sex of household head } \\
\hline Male & 228,501 & $10,470(4.4)$ & \multirow[t]{2}{*}{0.53} \\
\hline Female & 31,126 & $1414(4.5)$ & \\
\hline \multicolumn{4}{|c|}{ Mother read newspaper/magazine } \\
\hline Not at all & 179,129 & $9229(5.08)$ & \multirow[t]{4}{*}{$<0.001$} \\
\hline Less than once a week & 35,942 & 1409 (3.69) & \\
\hline At least once a week & 25,280 & $781(3.0)$ & \\
\hline Almost every day & 19,276 & 465 (1.99) & \\
\hline \multicolumn{4}{|c|}{ Mother heard family planning on radio } \\
\hline Yes & 39,958 & $1555(3.7)$ & \multirow[t]{2}{*}{$<0.001$} \\
\hline No & 219,669 & $10,329(4.55)$ & \\
\hline \multicolumn{4}{|c|}{ Mother heard family planning on TV } \\
\hline Yes & 130,519 & $4973(3.46)$ & \multirow[t]{2}{*}{$<0.001$} \\
\hline No & 129,108 & $6911(5.5)$ & \\
\hline \multicolumn{4}{|l|}{ Household wealth index } \\
\hline Poorest & 68,696 & $4253(6.27)$ & \multirow[t]{5}{*}{$<0.001$} \\
\hline Poorer & 61,436 & $3142(5.07)$ & \\
\hline Middle & 51,762 & $2174(4.2)$ & \\
\hline Richer & 42,946 & $1474(3.11)$ & \\
\hline Richest & 34,787 & $841(2.08)$ & \\
\hline \multicolumn{4}{|l|}{ Total children ever born } \\
\hline $1-4$ & 233,146 & $9706(4.0)$ & \multirow[t]{2}{*}{$<0.001$} \\
\hline$>4$ & 26,481 & 2178 (8.59) & \\
\hline \multicolumn{4}{|l|}{ Marital status } \\
\hline Not currently married & 3901 & $215(5.6)$ & \multirow[t]{2}{*}{0.009} \\
\hline $\begin{array}{l}\text { Currently married/living } \\
\text { with partner }\end{array}$ & 255,726 & 11,669 (4.39) & \\
\hline \multicolumn{4}{|l|}{ Employment status } \\
\hline Unemployed & 37,435 & $1654(4.2)$ & \multirow[t]{2}{*}{0.025} \\
\hline Employed & 7796 & $400(4.97)$ & \\
\hline Maternal age at first birth ( & ars) & & \\
\hline$<22$ & 158,233 & $7734(4.68)$ & $<0.001$ \\
\hline $22-28$ & 90,916 & 3723 (3.95) & \\
\hline$>28$ & 10,478 & $427(4.1)$ & \\
\hline
\end{tabular}

${ }^{\text {a }}$ Weighted percentage.

Table 2

Child factors of under 5 mortalities in India $(\mathrm{N}=259,627)$.

\begin{tabular}{llll}
\hline Variable & Number of children & Under 5 mortality n $(\%)^{\mathrm{a}}$ & P value \\
\hline Birth order & & & \\
$1-3$ & 217,489 & $9150(4.04)$ & $<0.001$ \\
$4-6$ & 36,759 & $2187(6.02)$ & \\
$>6$ & 5379 & $547(11.0)$ & $<0.001$ \\
Sex of child & & $6493(4.66)$ & \\
Male & 135,102 & $5391(4.14)$ & $<0.001$ \\
Female & 124,525 & & \\
Size of child & & & \\
Large & 44,094 & $1862(3.96)$ & \\
Average & 177,739 & $6609(3.56)$ & \\
Small & 31,380 & $2504(7.9)$ & \\
\hline
\end{tabular}

a Weighted percentage.
b Woman's own opinion about the size of her baby. 
which results in the timely achievement of growth milestones.

High under-five mortality among boys compared to girls is well established in literature due to the difference in genetic makeup, which makes boy child more susceptible to infections and pre-mature death. Women's empowerment by more comprehensive health education coverage, reinforcement of positive health behaviours, promotion of breastfeeding and family planning services can help address the underlying causes of under-five mortality.

A limitation of this study is the retrospective nature of the data collected. Recall bias and social desirability bias could have been encountered while interviewing mothers.

\section{Conclusion}

The prevalence of under-five mortality was high in India and this study adds to the understanding of drivers of under-five mortality and its associated factors. Healthcare programmes and policies should be explicitly designed to incorporate individual-level interventions focusing on young mothers to improve child survival in India.

\section{Declaration of competing interest}

None.

\section{References}

1 World Health Organization. The global health observatory. https://www.who.int/d ata/gho/indicator-metadata-registry/imr-details/7; 2016. Accessed June 8, 2021 Accessed.
2 United Nations Children's Fund. Levels and trends in child mortality. Under five Mortal Rep. 2020:14.

3 Bora JK. Factors explaining regional variation in under-five mortality in India: an evidence from NFHS-4. Health Place. 2020;64(64):1-11. https://doi.org/10.1016/j. healthplace.2020.102363 (2020).

4 United Nations Developmet Programme. The 17 Goals|Sustainable Development. 2015.

5 Kumar P, Singhal N. Mapping neonatal and under-5 mortality in India. Lancet. 2020; 395(10237):1591-1593.

6 International Institute for Population Sciences. National Family Health Survey. 2016. India.

7 Monden CWS, Smits J. Maternal education is associated with reduced female disadvantages in under-five mortality in sub-Saharan Africa and southern Asia. Int $J$ Epidemiol. 2013;42(1):211-218. https://doi.org/10.1093/ije/dys201.

8 Buor D. Mothers' education and childhood mortality in Ghana. Health Pol. 2003;64 (3):297-309. https://doi.org/10.1016/S0168-8510(02)00178-1.

9 Semba RD, de Pee S, Sun K, Sari M, Akhter NBM. Effect of parental formal education on risk of child stunting in Indonesia and Bangladesh: a cross-sectional study. Lancet. 2008;371(9609):322-328.

10 Monazza A, Kingdon GG. Parental education and child health - understanding the pathways of impact in Pakistan. World Dev. 2012;40(10):2012-2032.

11 Sinha S, Aggarwal AR, Osmond C, Fall CHD, Bhargava SK, Sachdev HS. Maternal age at childbirth and perinatal and under-five mortality in a prospective birth cohort from Delhi. Indian Pediatr. 2016;53(10):871-877. https://doi.org/10.1007/s13312016-0950-9.

12 Raj A, McDougal LRM. Effects of young maternal age and short interpregnancy interval on infant mortality in South Asia. Int J Gynaecol Obstet. 2014;124(1):86-87.

13 Ettarh RR, Kimani J. Determinants of under-five mortality in rural and urban Kenya. Rural Rem Health. 2012;12(1):1-9.

14 Yaya S, Uthman OA, Okonofua F, Bishwajit G. Decomposing the rural-urban gap in the factors of under-five mortality in sub-Saharan Africa? Evidence from 35 countries. BMC Publ Health. 2019;19(1):1-10. https://doi.org/10.1186/s12889-0196940-9.

15 Ekholuenetale M, Wegbom AI, Tudeme G, Onikan A. Household factors associated with infant and under-five mortality in sub-Saharan Africa countries. IJCCEP. 2020; 14(1):1-15. https://doi.org/10.1186/s40723-020-00075-1. 